\title{
On the use of the post-closure methods uncertainty band to evaluate the performance of land surface models against eddy covariance flux data
}

\author{
J. Ingwersen ${ }^{1}$, K. Imukova ${ }^{1}$, P. Högy ${ }^{2}$, and T. Streck ${ }^{1}$ \\ ${ }^{1}$ Institute of Soil Science and Land Evaluation, Universität Hohenheim, 70593 Stuttgart, Germany \\ ${ }^{2}$ Institute of Landscape and Plant Ecology, Universität Hohenheim, 70593 Stuttgart, Germany \\ Correspondence to: J. Ingwersen (joachim.ingwersen@uni-hohenheim.de)
}

Received: 27 October 2014 - Published in Biogeosciences Discuss.: 9 December 2014

Revised: 16 March 2015 - Accepted: 19 March 2015 - Published: 17 April 2015

\begin{abstract}
The energy balance of eddy covariance (EC) flux data is normally not closed. Therefore, at least if used for modelling, EC flux data are usually post-closed, i.e. the measured turbulent fluxes are adjusted so as to close the energy balance. At the current state of knowledge, however, it is not clear how to partition the missing energy in the right way. Eddy flux data therefore contain some uncertainty due to the unknown nature of the energy balance gap, which should be considered in model evaluation and the interpretation of simulation results. We propose to construct the post-closure methods uncertainty band (PUB), which essentially designates the differences between non-adjusted flux data and flux data adjusted with the three post-closure methods (Bowen ratio, latent heat flux (LE) and sensible heat flux $(H)$ method). To demonstrate this approach, simulations with the NOAHMP land surface model were evaluated based on EC measurements conducted at a winter wheat stand in southwest Germany in 2011, and the performance of the Jarvis and Ball-Berry stomatal resistance scheme was compared. The width of the PUB of the LE was up to $110 \mathrm{~W} \mathrm{~m}^{-2}(21 \%$ of net radiation). Our study shows that it is crucial to account for the uncertainty in EC flux data originating from lacking energy balance closure. Working with only a single post-closing method might result in severe misinterpretations in model-data comparisons.
\end{abstract}

\section{Introduction}

The eddy covariance (EC) technique is used worldwide to measure surface energy and matter fluxes. Until the 1980s, its application was restricted to a small circle of micrometeorologists. The equipment was expensive, its operation needed many years of experience, and data processing was complex and computationally demanding. During the last three decades, however, the installation and operation of EC flux stations has increasingly become "plug and play", and the development of software packages such as TK3 (Mauder and Foken, 2011) or EddyPro (LI-COR Inc., 2012) has allowed for non-micrometeorologists to process and evaluate EC data. This has led to a widespread use of the EC technique. Nowadays, the method is used by a broad community of scientists. It is applied by meteorologists, agronomists, biologists, hydrologists, forest and environmental scientists, geographers, etc. An impressive example of its worldwide use is the global trace gas flux network FLUXNET, which consists today of more than 400 EC stations dispersed across most of the world's climatic zones and biomes (Baldocchi et al., 2012).

The EC method is based on the assumption that the transport of energy and matter close to the land surface within the boundary layer is fully turbulent. Under (quasi-)stationary conditions, with a homogeneous surface and some less important assumptions, the sensible heat flux $\left(H, \mathrm{~W} \mathrm{~m}^{-2}\right)$ and the latent heat flux $\left(\lambda E, \mathrm{~W} \mathrm{~m}^{-2}\right)$ can be determined by measuring the covariance of the scalar variable of interest and the vertical wind speed $\left(w, \mathrm{~m} \mathrm{~s}^{-1}\right)$ according to Eqs. (1) and (2) 
as follows:

$H=\rho C_{p} \overline{\theta^{\prime} w^{\prime}}$,

$\lambda E=\rho \overline{q^{\prime} w^{\prime}}$.

For $H$, the scalar of interest is the potential temperature $(\theta, \mathrm{K})$. In the case of $\lambda E$, it is the specific humidity of air $\left(q, \mathrm{~kg} \mathrm{~kg}^{-1}\right)$. The symbol $\rho$ denotes air density $(\mathrm{kg}$ $\left.\mathrm{m}^{-3}\right)$, assumed constant, and $C_{p}$ is the heat capacity of air $\left(\mathrm{J} \mathrm{kg}^{-1} \mathrm{~K}^{-1}\right)$. Besides measuring these turbulent fluxes, EC stations are usually equipped with a net radiometer $\left(R_{\mathrm{N}}, \mathrm{W} \mathrm{m}^{-2}\right)$ and devices for measuring the soil heat flux $\left(G, \mathrm{~W} \mathrm{~m}^{-2}\right)$. These two measurements are used to evaluate the energy balance closure (EBC) of the EC flux data. Under ideal conditions,

$R_{\mathrm{N}}-G=\lambda E+H$.

The left-hand side of Eq. (3) is termed the available energy, and the right-hand term is the sum of the turbulent fluxes. With measured data, however, this equation is rarely fulfilled. Typically, the sum of the measured turbulent fluxes is lower than the measured available energy. The degree of EBC is often expressed as the energy balance ratio (EBR):

$\mathrm{EBR}=\frac{\lambda E+H}{R_{\mathrm{N}}-G}$.

The energy imbalance is typically in the range of $10-30 \%$ of the available energy (Wilson et al., 2002; Twine et al., 2000). This means that, in terms of energy flux, on a sunny summer day the imbalance can reach values of up to $150 \mathrm{~W} \mathrm{~m}^{-2}$ over a crop stand. Possible reasons discussed for the imbalance in the literature (e.g. Foken, 2008; Twine et al., 2000) can be assigned to two types: (I) measurement errors and (II) errors due to invalid assumptions. There is growing evidence that measurement errors cannot fully explain the systematic energy gap of the EC flux data (Foken, 2008). Type II errors include unconsidered energy storage terms or neglected energy fluxes such as photosynthesis, which are usually not determined with conventional EC systems. The assumption of fully turbulent transport might be severely violated during stable conditions or due to the presence of significant advection arising from horizontal flow convergence/divergence or a non-zero vertical wind speed (Oncley et al., 2007). Very recently, mesoscale circulations induced by landscape-scale heterogeneity have been suggested as a potential candidate to explain the systematic underestimation of turbulent fluxes (Mauder et al., 2013; Stoy et al., 2013). Due to their low frequency, mesoscale circulations cannot be detected with a single EC station and the typical averaging time of half an hour.

EC flux data are used, for example, to test and calibrate land surface models (Blyth et al., 2010; Gerken et al., 2012; Gielen et al., 2010; Ingwersen et al., 2011). In these types of studies, the energy balance of EC flux data is usually postclosed, i.e. the measured turbulent fluxes are adjusted ex post so as to force closure of the energy balance. At our current state of knowledge, however, it is unclear how to partition the missing energy. This requires modellers to make assumptions at this point, the most common being that the missing turbulent fluxes have the same Bowen ratio as the measured fluxes. This method is known as the Bowen ratio method (Barr et al., 1994; Blanken et al., 1997; Twine et al., 2000). It has been applied by, for example, Blyth et al. (2010), Alavi et al. (2010), Gerken et al. (2012), Ingwersen et al. (2011), and Winter and Eltahir (2010). A second, less often applied method is to fully assign the missing energy to the latent heat flux (LE post-closure method; Falge et al., 2005; Chen et al., 2007). In a few studies, the authors decided to use the raw flux data without closing the energy balance. This decision to use a third method was made because either the authors were interested in flux patterns rather than total fluxes (Carrer et al., 2012) or they had doubts about the correctness of the Bowen ratio method (Staudt et al., 2010). Recently, based on arguments raised by Foken (2008) and experimental findings of Mauder and Foken (2006), a fourth method was proposed. It has been termed the sensible heat flux method ( $H$ postclosure method; Ingwersen et al., 2011) and the method fully assigns the missing energy to the sensible heat flux. Studies that give experimental indications on the robustness of the $H$ method are rare. Foken (2008) argued that large eddies (mesoscale circulations), which cannot be captured by a single EC station and a covariance averaging time of half an hour as mentioned above, may significantly contribute to the total turbulent flux. Mauder and Foken (2006) evaluated EC flux data of the LITFASS-2003 experiment. The authors observed that the energy residual vanished almost completely if the flux averaging time was extended from $30 \mathrm{~min}$ (shortwave eddies) over $24 \mathrm{~h}$ to 5 days (longwave eddies). The averaging time had a minor effect on the latent heat flux, but the sensible heat flux nearly doubled. Hence, in that data set, the energy gap could be mainly assigned to sensible heat. The approach to increase the averaging time for computing the covariance to $24 \mathrm{~h}$ is questionable, because it appears that this procedure violates the fundamental assumption of stationarity. The authors argue that stationarity can be still assumed, because for the investigated 16-day time series the diurnal cycle was similar each day, and the trend of adjacent averages, which is the crucial stationarity criterion for the EC method, was smaller for $24 \mathrm{~h}$ values than for $30 \mathrm{~min}$ values. The finding that at some sites the energy residual may consist to a large extent of sensible heat was recently supported by an in-depth evaluation of additional EC flux data of the LITFASS-2003 experiment acquired over six different land use types (Charuchittipan et al., 2014).

Currently, the standard approach in modelling studies is (1) to adjust the EC flux data with one post-closure (most often with the Bowen ratio) method; (2) to indicate this postclosure method in the "Material and methods" section; and (3) to evaluate model performance against the resulting data set, neglecting the possible substantial error originating from 
the choice of the post-closure method (Gerken et al., 2012; Alavi et al., 2010; Ingwersen et al., 2011). Only rarely has the error originating from the post-closure method been reported in the literature. Hayashi et al. (2010) used the arithmetic average of raw flux and Bowen ratio-adjusted fluxes as a measure of uncertainty. Falge et al. (2005) as well as Spank et al. (2013) plotted the difference between LE-adjusted and non-adjusted flux data as a grey band to indicate the postclosure method error of the latent heat flux measurements. Our approach follows the same concept as the latter two, but our method goes further in three aspects: (1) we extend the approach for the sensible heat flux, (2) we include all three commonly used post-closure methods, and (3) we present quantitative measures to report the performance of the model with regard to the uncertainty originating from the post-closure method. We hope that this approach will help in avoiding premature conclusions when models are evaluated and simulation results interpreted.

\section{Material and methods}

\subsection{Study site and eddy covariance flux measurements}

The site under study and the EC flux measurements have been described in detail elsewhere (Ingwersen et al., 2011). In brief, the study site is located in southwest Germany $\left(48.92^{\circ} \mathrm{N}, 8.70^{\circ} \mathrm{E}\right)$. The size of the field is $425 \mathrm{~m} \times 350 \mathrm{~m}$. The altitude is $320 \mathrm{~m}$ above sea level, and the terrain is open and flat. The prevailing wind direction is southwesterly. In 2011, winter wheat (Triticum aestivum L. cv. Akteur) was grown. It was drilled on 11 October 2010 and harvested on 29 July 2011. Three weeks before harvest (beginning of July), the winter wheat entered the ripening phase and became progressively senescent. Soil is classified as Stagnic Luvisol (IUSS Working Group WRB, 2007). Parent material is loess with a thickness of several metres. Mean annual temperature is 9 to $10^{\circ} \mathrm{C}$, and mean annual precipitation varies between 720 and $830 \mathrm{~mm}$.

From 24 March to 22 July 2011, surface energy fluxes (net radiation, sensible, latent, and soil heat flux) were measured with an EC station, which was operated in the centre of the field. The station was equipped with a LI-COR 7500 open-path infrared $\mathrm{CO}_{2} / \mathrm{H}_{2} \mathrm{O}$ gas analyser (LI-COR Biosciences Inc., USA), CSAT3 3D sonic anemometer (Campbell Scientific Inc., UK), an NR01 four-component net radiation sensor (Hukseflux Thermal Sensors, the Netherlands), an air temperature and humidity probe (HMP45C, Vaisala Inc., USA), and a tipping bucket (ARG100, Environmental Measurements Ltd, UK). Close to the station, three soil heat flux plates (HFP01, Hukseflux Thermal Sensors, the Netherlands) were installed $8 \mathrm{~cm}$ below ground surface. Soil temperature and soil water content needed for computing the heat storage above the heat flux plate were measured with thermistor temperature probes (model 107, Campbell Sci- entific Inc., UK) installed at 2 and $6 \mathrm{~cm}$ depth and with a TDR probe (CS616, Campbell Scientific Inc., UK) installed at $5 \mathrm{~cm}$ depth. The EC data were processed using the software package TK3.1 (Mauder and Foken, 2011). The latent and sensible heat fluxes were computed from 30 min covariances between vertical wind velocity and the corresponding scalar (air humidity or air temperature). In the TK3.1 software we used the following settings: spike detection (i.e. values exceeding 4.5 times the standard deviation of the last 15 values were labelled as spike); a planar fit method for coordinate rotation with time periods between 7 and 12 days; a Moore (1986) correction except for the longitudinal separation, which was taken into account by maximizing the covariances; a Schontanus et al. (1983) procedure for converting the sonic into actual temperature; and density correction as suggested by Webb et al. (1980). The version TK3.1 includes the computation of the random measurement error as the sum of instrument noise and stochastic error (Mauder et al., 2013). For data quality analysis we used the nine-flag system of Foken (1999). Half-hourly fluxes with flag 7-9 (poorquality data) for friction velocity, sensible heat flux, or latent heat flux were excluded from data analysis.

Additionally, in late autumn 2010, five subplots of $4 \mathrm{~m}^{2}$ were randomly selected and permanently marked to track total leaf area index (LAI; green plus senescent LAI including stems). LAI was measured biweekly from the end of March 2011 (due to the harsh winter) until crop maturity at the central square metre of every subplot using an LAI-2000 plant canopy analyser (LI-COR Biosciences Inc., USA).

\subsection{Post-closure methods uncertainty band}

The post-closure methods uncertainty band (PUB) is a proxy for the possible systematic error of EC flux data due to the unknown nature of the energy balance gap and the therefore open question of which post-closure method fits best at the site under study. We define here that a PUB must basically fulfil two criteria: (1) the lower bound of the band must be formed by the non-adjusted measured raw fluxes, and (2) in the case of EBR $<1$ the width of the PUB must be nonzero for both the latent and sensible heat flux. The upper and lower bounds of the band are constructed from the difference between raw fluxes and fluxes adjusted by one of the three post-closure methods. Figure 1 illustrates this approach for one lower and upper bound combination. The figure shows the diurnal course of simulated and measured latent and sensible heat fluxes over a winter wheat stand. The measured data were adjusted to the Bowen ratio method (line with open triangles). The difference between the Bowen ratio method and the non-adjusted fluxes (line with closed circles), the grey band between the two lines, forms the PUB. The second possible lower and upper bound combination is to use the LE and $H$ method to construct the PUB. In the case of latent heat flux, the data adjusted with the LE method form the upper bound. In the case of the sensible heat flux, the 
contrary holds true. The upper bound is formed by the $H$ adjusted data. Note that in the $H$ method, the adjusted latent heat fluxes are identical with the raw fluxes, whereas in the LE method, the adjusted sensible heat fluxes are the same as the raw ones. The four other possible bound combinations result either in a zero PUB width for one of the two turbulent fluxes or the lower bound is not formed by the raw fluxes (Table 1). To be able to visually construct both possible PUBs, the adjusted flux that was not used in the computation of the PUB is indicated by symbols. Furthermore, to indicate the measurement error due to instrumental noise and the number of independent observations used in calculating the covariances, the random error is plotted as error bars on the measured raw fluxes.

For the construction of the PUB, only half-hourly fluxes within a predefined EBR range were considered:

$\tau<\mathrm{EBR}<2-\tau$.

Here, $\tau$ is the threshold of EBR, ranging from zero to two, that constrains the data analysis to a certain EBR window. A $\tau$ value of 0.5 means, for example, that only half-hourly fluxes with an EBR larger than 0.5 and smaller than 1.5 are considered.

Besides the above-mentioned graphical representation, we suggest the following two criteria to evaluate the simulation results with respect to the PUB:

- Band coverage:

The band coverage (BC) is, by definition, the percentage of simulated values that are covered by the upper and lower bound of the post-closure methods uncertainty band.

- Bound preference:

The bound preference (BP) quantifies the average position of a simulated value within the PUB. The bound preference of the $i$ th simulated value $\left(P_{i}\right)$ is calculated as follows:

$\mathrm{BP}_{i}=\frac{2\left(P_{i}-O_{\mathrm{LB}, i}\right)}{O_{\mathrm{UB}, i}-O_{\mathrm{LB}, i}}-1$,

where $O_{\mathrm{LB}, i}$ and $O_{\mathrm{UB}, i}$ are the value of the $i$ th lower and upper bound, respectively. A negative value of BP indicates that the simulated flux is closer to the lower bound, whereas a positive value indicates that the model has a preference for the upper bound. A value of zero indicates that the simulated value is midway between both bands. A BP outside the range of -1 to +1 indicates that the simulation is not enclosed by the uncertainty band. To constrain the calculation to daytime values, BC and BP were computed only for mean diurnal half-hourly fluxes of sensible and latent heat larger than 20 and $40 \mathrm{~W} \mathrm{~m}^{-2}$, respectively. The BP of the monthly mean diurnal course of a flux was computed from the median of mean half-hourly BP of that month.

\subsection{The NOAH-MP land surface model}

The proposed approach is demonstrated for simulations performed with the NOAH land surface model (LSM). The NOAH LSM is a well-established and widely used model. It is the land surface component of atmospheric models such as the Mesoscale Meteorology Model 5 (MM5; Dudhia, 1993), and the Weather Research and Forecasting (WRF; e.g. Skamarock et al., 2008). Recently, the NOAH LSM has been extended by multiple-physics options (NOAHMP) and an improved implementation to consider land surface heterogeneities (Niu et al., 2011). In the present study we use NOAH-MP v1.1 (http://www.ral.ucar.edu/research/ land/technology/noahmp_lsm.php). In NOAH-MP, the land surface heterogeneity is described with a semi-tile subgrid scheme. This means that shortwave radiation transfer is computed over the entire grid cell, while longwave radiation, latent heat, sensible heat, and ground heat flux are computed separately over two tiles (vegetated or bare ground area; Niu et al., 2011). Among the many multi-physics options, the user can choose between two schemes for computing the stomatal resistance $\left(r_{\mathrm{s}}\right)$ : (1) the empirical Jarvis scheme, which was already implemented in previous NOAH LSM versions, or (2) the photosynthesis-based Ball-Berry scheme. $r_{\mathrm{s}}$ is a key variable for transpiration. It strongly controls the energy partitioning at the land surface.

The Jarvis scheme computes $r_{\mathrm{s}}$ as the reciprocal product of four reduction functions, and the minimum stomatal resistance $\left(r_{\mathrm{s}, \min }\right)$,

$r_{\mathrm{s}}=\frac{1}{\mathrm{LAI} F_{1} F_{2} F_{3} F_{4}} r_{\mathrm{s}, \min }$,

where $F_{1}, F_{2}, F_{3}$, and $F_{4}$ are functions bounded between zero and one as lower and upper values. The four functions consider the effects of solar radiation $\left(F_{1}\right)$, vapour pressure deficit $\left(F_{2}\right)$, air temperature $\left(F_{3}\right)$, and soil moisture stress $\left(F_{4}\right)$. The variable LAI denotes the (green) leaf area index $\left(\mathrm{m}^{2} \mathrm{~m}^{-2}\right)$. For the computation of $F_{1}$ to $F_{4}$, we refer the reader to Chen and Dudhia (2001).

In the Ball-Berry scheme, $r_{\mathrm{s}}$ is a function of the photosynthesis rate,

$\frac{1}{r_{\mathrm{s}}}=m \frac{A}{c_{\mathrm{air}}} \frac{e_{\mathrm{air}}}{e_{\mathrm{sat}}\left(T_{\mathrm{v}}\right)} P_{\mathrm{air}}+g_{\mathrm{min}}$,

where $A\left(\mu \mathrm{mol} \mathrm{m} \mathrm{m}^{-2} \mathrm{~s}^{-1}\right)$ is the rate of photosynthesis per unit LAI, $c_{\text {air }}$ the carbon dioxide $\left(\mathrm{CO}_{2}\right)$ concentration at the leaf surface $(\mathrm{Pa}), P_{\text {air }}$ the surface air pressure $(\mathrm{Pa}), e_{\text {air }}$ the vapour pressure at the leaf surface $(\mathrm{Pa}), e_{\mathrm{sat}}\left(T_{\mathrm{v}}\right)$ the saturation vapour pressure inside the leaf $(\mathrm{Pa})$, and $g_{\min }$ denotes the minimum stomatal conductance $\left(\mu \mathrm{mol} \mathrm{m}^{-2} \mathrm{~s}^{-1}\right)$. The symbol $m$ (1) denotes an empirical parameter that relates transpiration to $\mathrm{CO}_{2}$ flux. $A$ is computed with the Farquhar model (Farquhar et al., 1980) as the minimum of the enzyme ribulose bisphosphate carboxylase/oxygenase (Ru- 

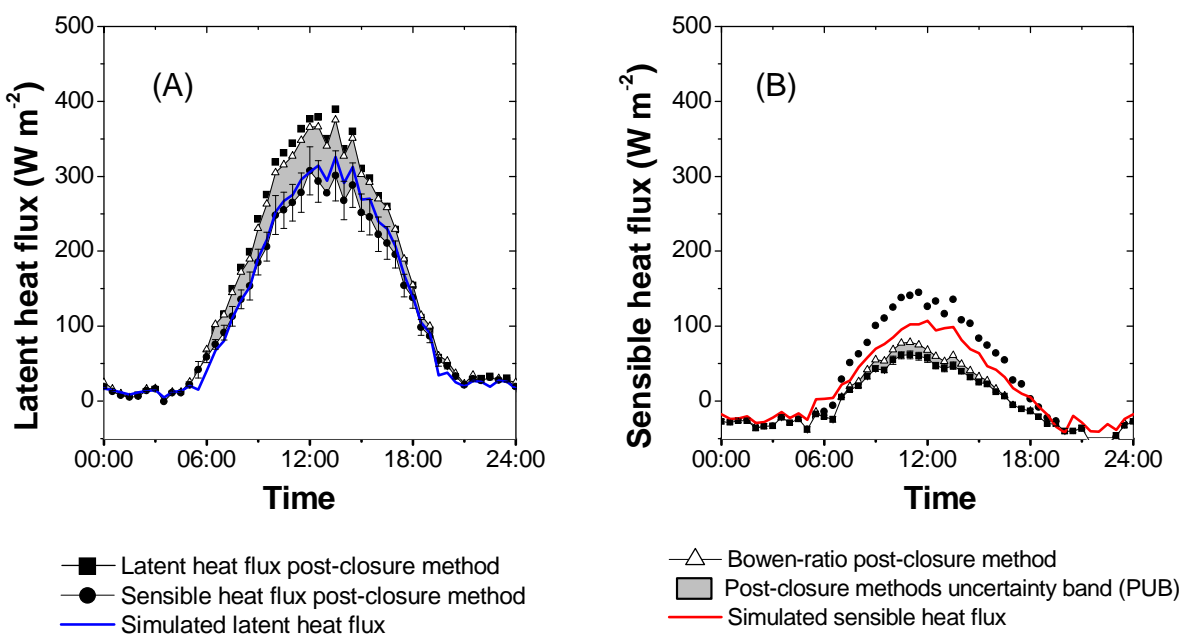

Figure 1. Illustration of the post-closure methods uncertainty band (PUB) to consider the systematic error in eddy covariance (EC) flux data. The grey band shows the PUB computed as the difference between Bowen ratio-adjusted and non-adjusted fluxes. The closed squares in (a) indicate the latent heat (LE) post-closed fluxes, and the close circles in (b) show the sensible heat $(H)$ post-closed data. The error bars indicate the random measurement error. In some cases, the error bars are smaller than the size of the symbol and therefore not visible. Note: in the case of latent heat flux, raw data and $H$ post-closed data are identical. In the case of sensible heat flux, LE post-closed data and raw data are identical.

Table 1. Overview of possible bound combinations to construct the post-closure methods uncertainty band (PUB). The upper and lower bound of the band are constructed from the difference between raw fluxes and fluxes adjusted by one of the three post-closure methods (Bowen ratio $(B)$, sensible heat $(H)$, and latent heat (LE) method).

\begin{tabular}{|c|c|c|c|c|c|}
\hline \multirow[t]{2}{*}{$\begin{array}{l}\text { Bound } \\
\text { combination }\end{array}$} & \multicolumn{2}{|c|}{$\begin{array}{c}\text { Lower bound }= \\
\text { measured flux }\end{array}$} & \multicolumn{2}{|c|}{ PUB width $>0$} & \multirow[t]{2}{*}{$\begin{array}{c}\text { Useful } \\
\text { combination }\end{array}$} \\
\hline & $\mathrm{LE}$ & $H$ & LE & $H$ & \\
\hline 1. $H-\mathrm{LE}$ & $\mathrm{y}$ & $\mathrm{y}$ & $\mathrm{y}$ & $\mathrm{y}$ & $\mathrm{y}$ \\
\hline 2. $H-\mathrm{B}$ & $\mathrm{y}$ & $\mathrm{n}$ & $\mathrm{y}$ & $\mathrm{y}$ & $\mathrm{n}$ \\
\hline 3. LE- $B$ & $\mathrm{n}$ & $\mathrm{y}$ & $\mathrm{y}$ & $\mathrm{y}$ & $\mathrm{n}$ \\
\hline 4. raw-LE & $\mathrm{y}$ & $\mathrm{y}$ & $\mathrm{y}$ & $\mathrm{n}$ & $\mathrm{n}$ \\
\hline 5. raw $-H$ & $\mathrm{y}$ & $\mathrm{y}$ & $\mathrm{n}$ & $\mathrm{y}$ & $\mathrm{n}$ \\
\hline 6. raw $-B$ & $\mathrm{y}$ & $\mathrm{y}$ & $\mathrm{y}$ & $\mathrm{y}$ & $\mathrm{y}$ \\
\hline
\end{tabular}

Note: y, yes; n, no.

BisCO) and light-limited rate. Moreover, a nitrogen (N) reduction factor ranging from zero to unity is included to consider N limitation. Receiving $168 \mathrm{~kg} \mathrm{~N}$ per hectare of fertilizer over the season, the winter wheat stand on our EC site is not $\mathrm{N}$-limited, and thus the $\mathrm{N}$ reduction factor was set to unity.

In the following we will demonstrate the application of the PUB approach by evaluating the performance of NOAHMP simulations to reproduce the EC flux data from a winter wheat stand and compare the performance of the Jarvis and Ball-Berry schemes. The simulation starts on day of drilling (11 October 2010) and ends on 22 July 2011 (about 1 week before final harvest at maturity). The soil profile was divided into four layers $(0-0.1,0.1-0.4,0.4-1.0$, and $1.0-2.0 \mathrm{~m})$. The initial soil temperatures of the four layers were $285,283,282$, and $282 \mathrm{~K}$. The initial soil water content was set to $24,30,41$, and 43 vol. \%. We used the USGS land use data set, vegetation type index was set to 2 (dryland cropland and pasture), and soil type index was 8 (silty clay loam). The multi-physics options used in the simulation are listed in Table 2. Among other options, we selected a predefined monthly LAI and fractional vegetated area (FVEG) data. Monthly (green) LAI were linearly derived from measured total LAI data (Fig. 2). From mid-June until mid-July we assumed that the green LAI declined linearly from 4.6 to

$\mathrm{FVEG}=1-\exp \left(-0.52 \mathrm{LAI}_{\mathrm{tot}}\right)$.

The model was forced with half-hourly weather data (wind speed, air temperature, air humidity, downwelling shortwave radiation, downwelling longwave radiation, and precipitation) acquired at the EC station. 
Table 2. Setting of the multi-physics options used in the NOAH-MP simulation.

\begin{tabular}{ll}
\hline Multi-physics option & Setting \\
\hline Vegetation model & opt_dveg =1: LAI and FVEG pre-defined in look-up table \\
Canopy stomatal resistance scheme & opt_crs =1 or 2: Ball-Berry (1) or Jarvis (2) scheme \\
Runoff and groundwater model & opt_btr =1: TOPMODEL-based simple groundwater model \\
Sensible heat exchange coefficient & opt_sfc=1: Based on Monin-Obukhov similarity theory \\
Supercooled liquid water & opt_frz=1: General form of the of the freezing-point depression equation (NY06) \\
Radiation transfer scheme & opt_rad=3: Gaps =1-FVEG \\
Lower boundary of soil temperature & opt_tbot =2: Constant temperature \\
Snow/soil temperature time scheme & opt_stc=1: Semi-implicit \\
\hline
\end{tabular}

LAI: (green) leaf area index; FVEG: fractional vegetated area.

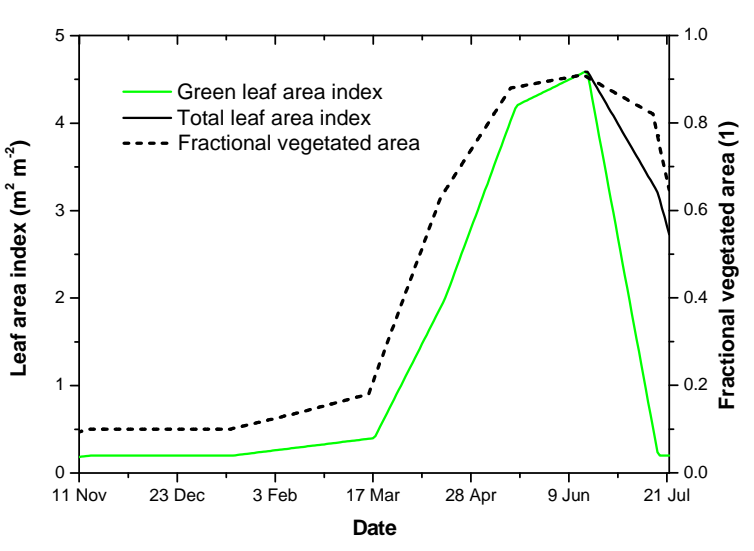

Figure 2. Prescribed dynamics of the green and total leaf area index and the fractional vegetated area used in NOAH-MP simulations. Note: until 15 June green and total leaf area index are the same.

\section{Results and discussion}

One of the first steps in constructing the PUB is to set $\tau$ (see Eq. 5). The choice of $\tau$ is a trade-off between the average EBR, i.e. the width of the PUB, and the number of data points remaining in the data set for model evaluation (Fig. 3). In our data set, at $\tau=03186$ (i.e. $100 \%$ ) half-hourly fluxes passed the quality filter, and the average EBR was $74 \%$. Increasing $\tau$ to 0.5 improved the EBR only slightly. At $\tau=0.55$, both lines cross, the EBR increases to $80 \%$, and $20 \%$ of the fluxes are excluded from the data analysis. Increasing $\tau$ to 0.8 improves EBR considerably (to $92 \%$ ) but strongly decreases the number of data points remaining in the data set. With this choice, $69 \%$ of the fluxes would not be considered in model evaluation. As a consequence, the mean monthly diurnal cycle of the energy fluxes deviate markedly from that with $\tau=0$ (Fig. 4). The diurnal cycle becomes less continuous and more scattered, and data gaps show up during the morning and evening hours. In the present study, as a compromise between the width of PUB and data loss, we set $\tau$ to 0.7 . With this choice, the EBR reaches $85 \%$, which corresponds well to the average EBR of EC FLUXNET data

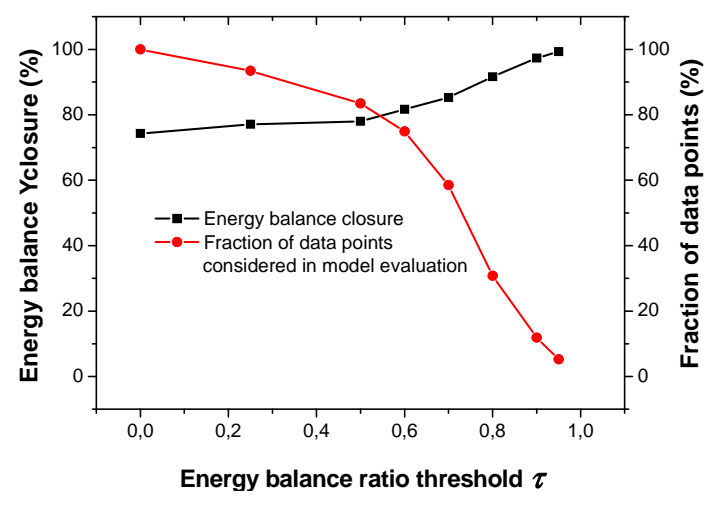

Figure 3. Effect of the energy balance ratio threshold $\tau$ on the energy balance closure and the fraction of data points remaining in the data set for model evaluation.

(Stoy et al., 2013). The diurnal cycle of the energy fluxes is still similar to that with $\tau=0$, and at $42 \%$ the data loss is in an intermediate range.

Figures 5 and 6 demonstrate the standard approach to using EC flux data in model evaluation. The two figures show the diurnal course of simulated and measured latent and sensible heat flux over a winter wheat field from April to July in 2011. The simulated turbulent fluxes are compared with one data set of measured fluxes, whereby the latent and sensible heat fluxes were adjusted on the basis of one post-closure method. In this example the commonly used Bowen ratio method was applied. With this method the modeller would come to the following interpretation: the Jarvis scheme matches nearly perfectly the measured latent heat fluxes in April. In May and June, however, the Jarvis scheme underestimates the observed latent heat fluxes. The agreement is less good in the morning and becomes better in the late afternoon. The tendency to underestimate the latent heat flux is even more pronounced with the Ball-Berry scheme. During the main growth period from April to June, fluxes simulated with the Ball-Berry scheme largely underestimate the latent heat flux. In July, the situation is different for both schemes. NOAH-MP also underestimates the latent 


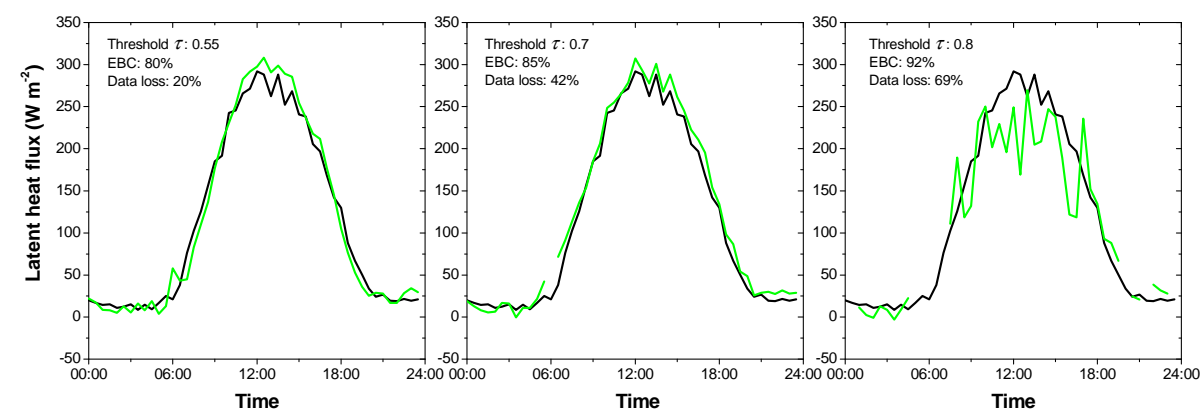

Figure 4. Effect of the energy balance ratio threshold $\tau$ on the pattern of the mean diurnal cycle of measured latent heat fluxes in May 2011. Only flux data with an energy balance ratio (EBR) $\tau<$ EBR $<2-\tau$ were used to compute the mean diurnal course (green line). The black line shows the mean diurnal course for $\tau=0$.

heat flux in the morning, but from noon to late afternoon both schemes, which produce very similar simulation results, overestimate the latent heat flux. The above-mentioned findings can be underlined by the classical performance criteria (see Table 3). The modelling efficiency (EF) of the Jarvis scheme is highest in April. The root-mean-square error (RMSE) is only $11.3 \mathrm{~W} \mathrm{~m}^{-2}$, and the simulation is nearly unbiased. In May and June both schemes deliver negatively biased latent heat fluxes. In July, the fluxes are positively biased. Nevertheless, in all months the EF is high (78 to $99 \%)$.

With regard to the sensible heat flux, NOAH-MP tends to overestimate the flux during the main growth period of winter wheat (Fig. 6). Simulations based on the Ball-Berry scheme largely overestimate the sensible heat flux from April to June. The bias ranges from 34.2 to $57 \mathrm{~W} \mathrm{~m}^{-2}$, and in May the EF becomes negative (Table 3). Simulations based on the Jarvis scheme also overestimate the sensible heat flux but not as strongly as those based on the Ball-Berry scheme. The EF is always higher than with the Ball-Berry scheme, and, particularly in the afternoon hours of April, the simulations match the measured fluxes fairly well. In July, simulations with both schemes underestimate the sensible heat flux during most of the daytime (Jarvis: bias $=-27.0 \mathrm{~W} \mathrm{~m}^{-2}$; BallBerry: bias $=-33.6 \mathrm{~W} \mathrm{~m}^{-2}$ ).

In summary, the modeller would come to the conclusion that the default parameterization of NOAH-MP is not suited to simulate the surface energy fluxes at this winter wheat site. The Jarvis scheme outperforms the Ball-Berry scheme but also leads to strong systematic errors. From April to June, NOAH-MP overestimates the latent heat flux and underestimates the sensible heat flux. In July, the situation is opposite. In a next step, the modeller would try to improve the simulations, e.g. by fine-tuning selected parameters within reasonable ranges. Ingwersen et al. (2011), for example, could distinctly improve NOAH simulations by replacing the de-

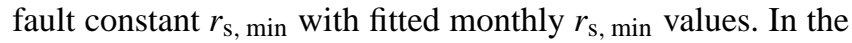
case of the Ball-Berry scheme an optimization of the empirical parameter $m$ (see Eq. 7) would most probably bring the observed and simulated fluxes into closer agreement. A fur- ther option is to search for multi-physics combinations that, with their default parameterization, lead to the best match of simulated and measured fluxes (Gayler et al., 2014).

Figures 7 to 10 show the same simulation results as above but now with the proposed PUB. First, we discuss the results based on the Bowen ratio PUB (Figs. 7 and 8). Over the daytime, the width of the PUB of the latent heat flux is on average 49.7, 59.0, 47.7, and $29.5 \mathrm{~W} \mathrm{~m}^{-2}$ in April, May, June, and July, respectively. The maximum width of the PUB is $88.0 \mathrm{~W} \mathrm{~m}^{-2}$ (17\% of net radiation) during noon in May. In May and June, latent heat fluxes simulated with the Jarvis scheme are well covered by the PUB (Table 4). In April, BC is only $35 \%$, and the Jarvis scheme has an upper bound preference $(\mathrm{BP}=0.95$, Table 4$)$; in May and June its preference changes to the lower bound ( $\mathrm{BP}=-0.29$ in May and -0.49 in June). The Ball-Berry scheme has a good BC in April, and a $\mathrm{BP}$ of -0.53 indicates that the simulation is on average enclosed by the PUB. In May and June, the BC is poor and the BP becomes smaller than -1 , pointing to a systematic underestimation of the latent heat flux though the fluxes are still in the range of the error bars. In July, the BC is low in both schemes, and in the early morning and afternoon the simulated fluxes are outside the PUB, with a BP markedly larger than unity pointing to a deficiency in the model.

The mean Bowen ratios were 0.17, 0.11, and 0.12 in April, May, and June, respectively, and increased over the ripening phase in July to 0.71 . Because of these low Bowen ratios during the main growth period (April to June), the Bowen postclosure method assigns the majority of the energy residual to the latent heat flux, which means that the PUB of the sensible heat becomes quite narrow (Fig. 8). Most of the time, both simulations do not fall within the PUB and are located above the upper bound. From April to June, the Ball-Berry scheme results in distinctly higher sensible heat fluxes than the Jarvis scheme. Its BP is significantly larger than unity for all three months. In May, the BP reaches a value of 11.38, indicating that the simulation results are far above the upper bound of the PUB. In July, the sensible heat fluxes simulated by both schemes are only poorly matched by the PUB $(\mathrm{BC}=5 \%)$, 

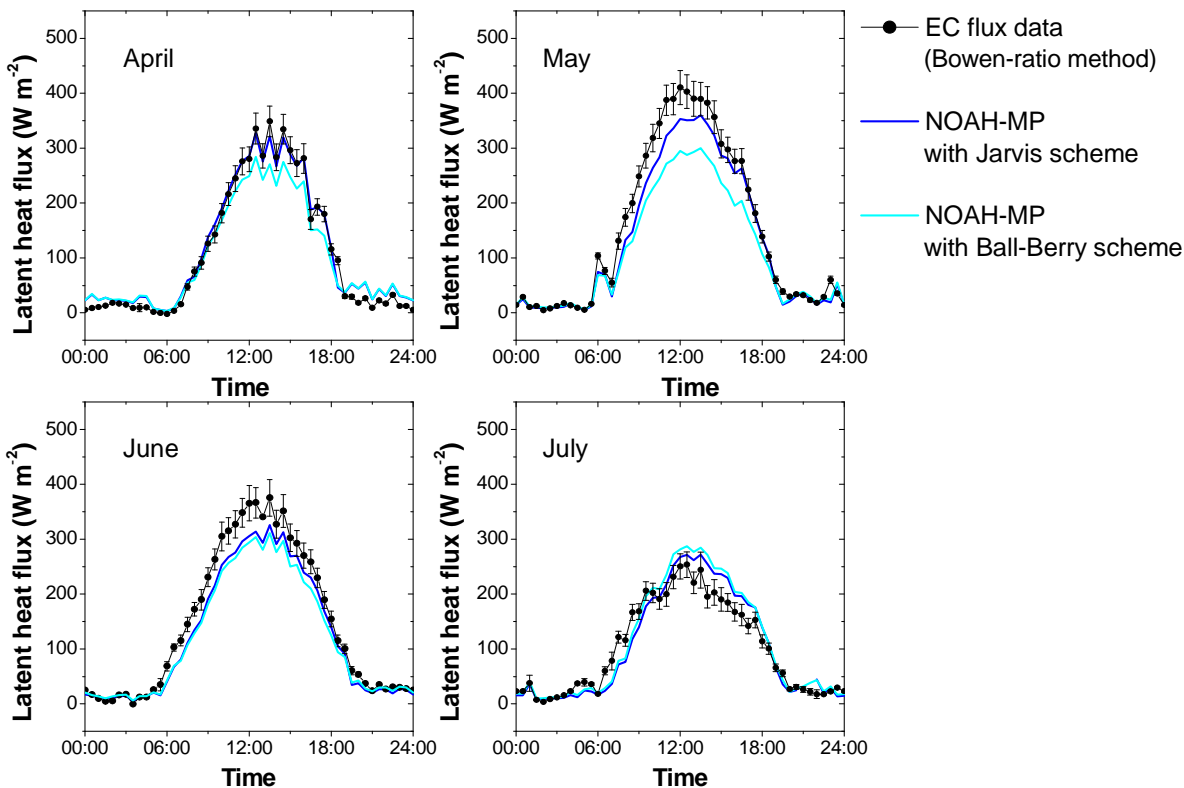

Figure 5. State-of-the art approach to compare simulated and measured eddy covariance (EC) flux data. The monthly average cycles of latent heat flux were computed based on Bowen ratio post-closed data. For modelling, the NOAH-MP land surface model was used in two configurations. The stomatal resistance was computed either with the empirical Jarvis scheme or the photosynthesis-based Ball-Berry scheme. The simulated fluxes are compared with measured EC flux data that were adjusted with the Bowen ratio method. The error bars indicate the random measurement error. In some cases, the error bars are smaller than the size of the symbol and therefore not visible.
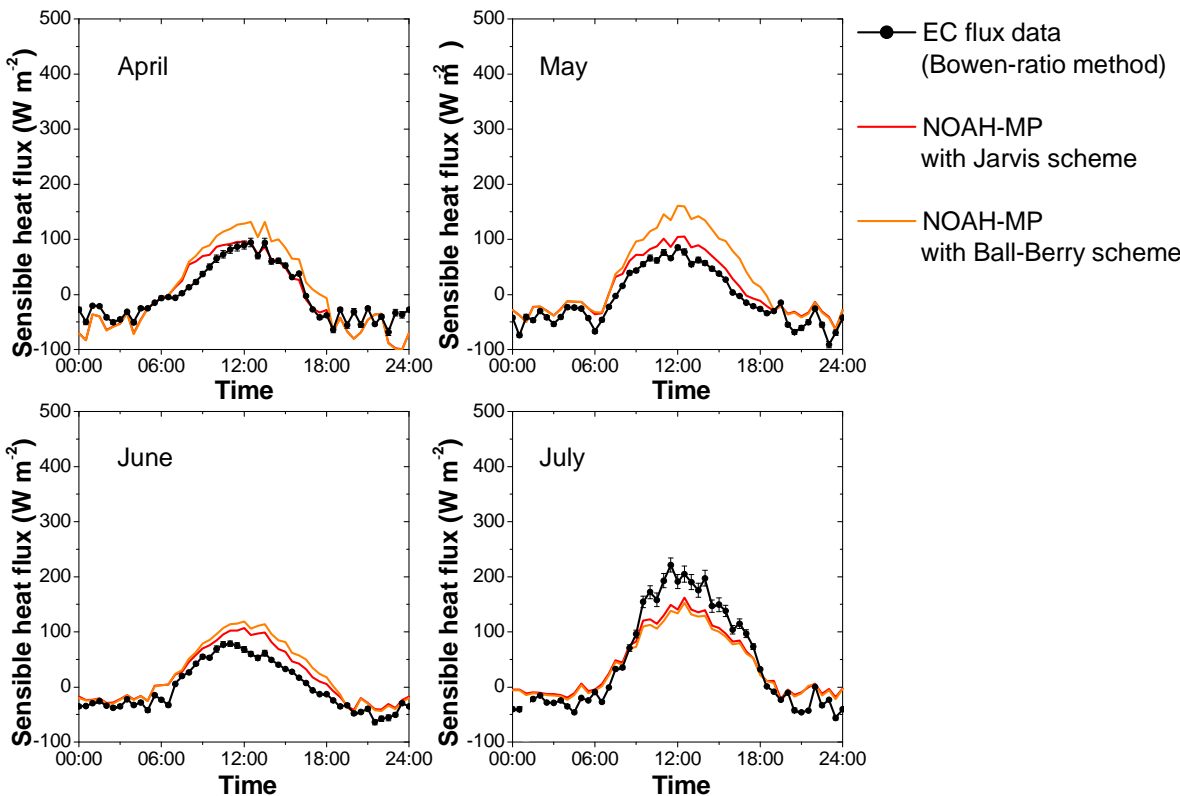

Figure 6. State-of-the art approach to compare simulated and measured eddy covariance flux data. The monthly average cycles of sensible heat flux were computed based on Bowen ratio post-closed data. For modelling, the NOAH-MP land surface model was used in two configurations. The stomatal resistance was computed either with the empirical Jarvis scheme or the photosynthesis-based Ball-Berry scheme. The simulated fluxes are compared with measured eddy covariance (EC) flux data that were adjusted with the Bowen ratio method. The error bars indicate the random measurement error. In some cases, the error bars are smaller than the size of the symbol and therefore not visible. 
Table 3. Model performance criteria for the simulation results presented in Figs. 5 and 6. For the computation of model efficiency, root mean square error (RMSE) and bias see, for example, Ingwersen et al. (2011). The performance criteria were computed for the daytime (06:00 to 18:00 UTC?).

\begin{tabular}{|c|c|c|c|c|c|c|}
\hline \multirow[t]{2}{*}{ Month } & \multicolumn{2}{|c|}{ Model efficiency (\%) } & \multicolumn{2}{|c|}{$\operatorname{RMSE}\left(\mathrm{W} \mathrm{m}^{-2}\right)$} & \multicolumn{2}{|c|}{$\operatorname{Bias}\left(\mathrm{W} \mathrm{m}^{-2}\right)$} \\
\hline & Jarvis & Ball-Berry & Jarvis & Ball-Berry & Jarvis & Ball-Berry \\
\hline \multicolumn{7}{|c|}{ Latent heat flux } \\
\hline April & 99 & 93 & 11.3 & 35.7 & 1.0 & -26.4 \\
\hline May & 96 & 83 & 40.9 & 81.4 & -36.3 & -76.0 \\
\hline June & 95 & 91 & 41.1 & 52.2 & -39.7 & -51.1 \\
\hline July & 84 & 78 & 34.1 & 39.1 & 7.4 & 18.3 \\
\hline \multicolumn{7}{|c|}{ Sensible heat flux } \\
\hline April & 91 & 59 & 16.8 & 36.2 & 8.9 & 34.2 \\
\hline May & 78 & -45 & 23.3 & 60.2 & 22.5 & 57.0 \\
\hline June & 69 & 36 & 26.9 & 38.4 & 25.4 & 36.6 \\
\hline July & 92 & 89 & 38.9 & 45.2 & -27.0 & -33.6 \\
\hline
\end{tabular}
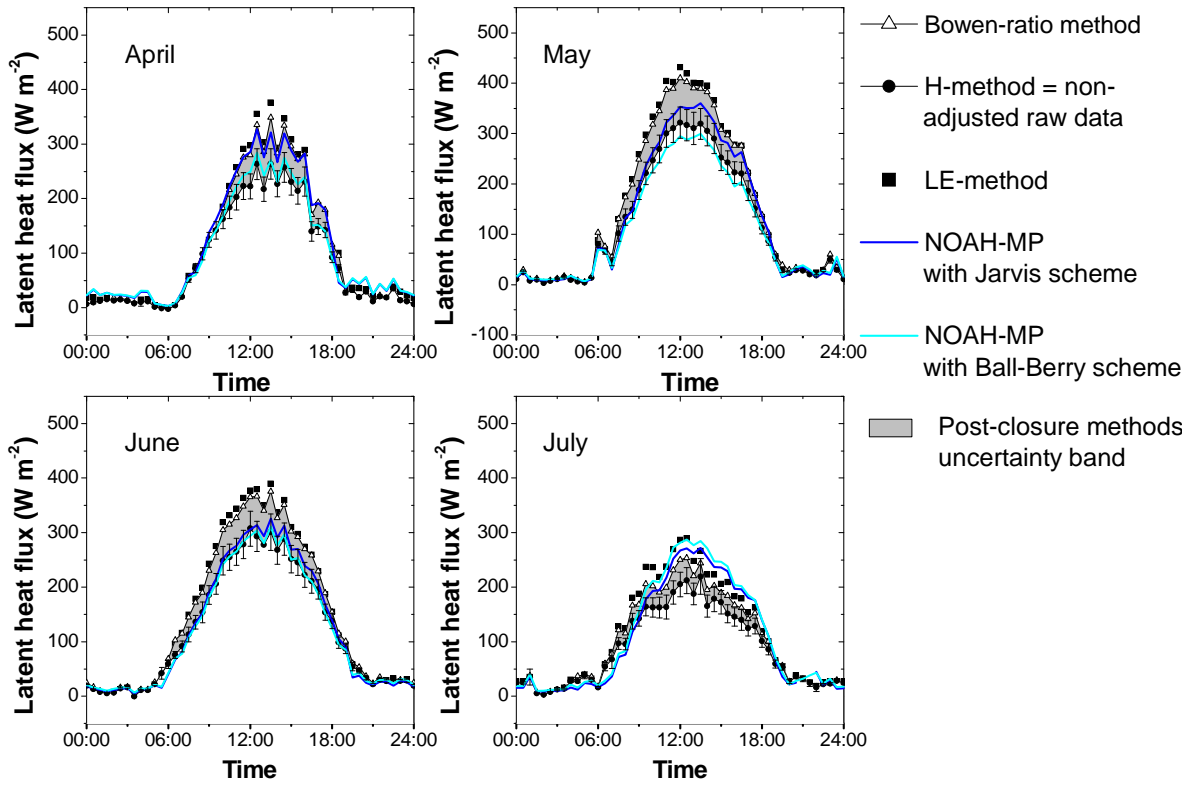

Post-closure methods uncertainty band

Figure 7. Measured and simulated monthly average diurnal cycles of latent heat flux over a winter wheat stand in southwest Germany. For modelling, the NOAH-MP land surface model was used in two configurations. The stomatal resistance was computed either with the empirical Jarvis scheme or the photosynthesis-based Ball-Berry scheme. The grey band shows the post-closure methods uncertainty band computed as the difference between the raw and Bowen ratio-adjusted fluxes. The error bars indicate the random measurement error. In some cases, the error bars are smaller than the size of the symbol and therefore not visible.

but now the BP becomes negative, and the measured sensible heat fluxes are systematically underestimated from late morning to late afternoon.

As mentioned above, the Bowen ratio was low during the main growth period. Therefore, the $H$-LE method delivers for the latent heat flux very similar PUBs as the Bowen ratio method (Figs. 7 and 9). The width of the PUB of the LEadjusted latent heat fluxes is somewhat higher than the fluxes adjusted with the Bowen ratio method and is on average 58.3, 68.7, 56.4, and 51.0 $\mathrm{W} \mathrm{m}^{-2}$ in April, May, June, and July, respectively. The maximum width of the PUB increases to $110.0 \mathrm{~W} \mathrm{~m}^{-2}$ (21\% of net radiation) and is also reached in noon in May. With regard to the sensible heat flux, in contrast, the difference between the Bowen and $H$-LE PUB is enormous (Figs. 8 and 10). Because the $H$-LE method assigns the entire energy residual to the sensible heat, the PUB becomes very broad during the daytime. The overall BC improves with either scheme (Table 5). In April, both schemes lead to a systematical overestimation of simulated sensible heat fluxes during the early morning hours. Yet, from 10:00 

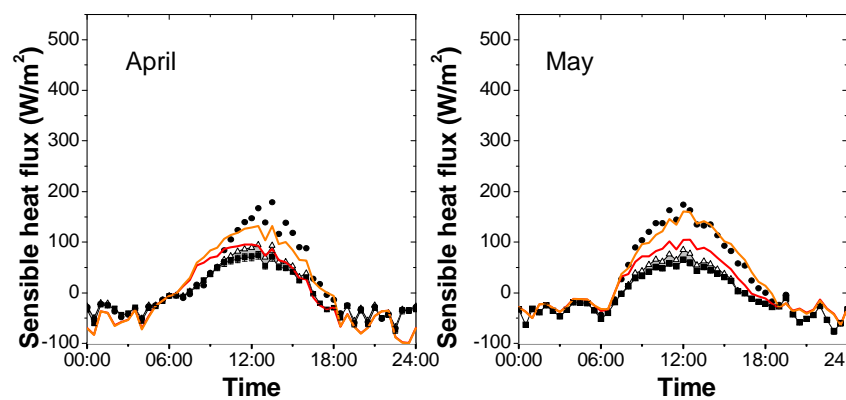

- H-method
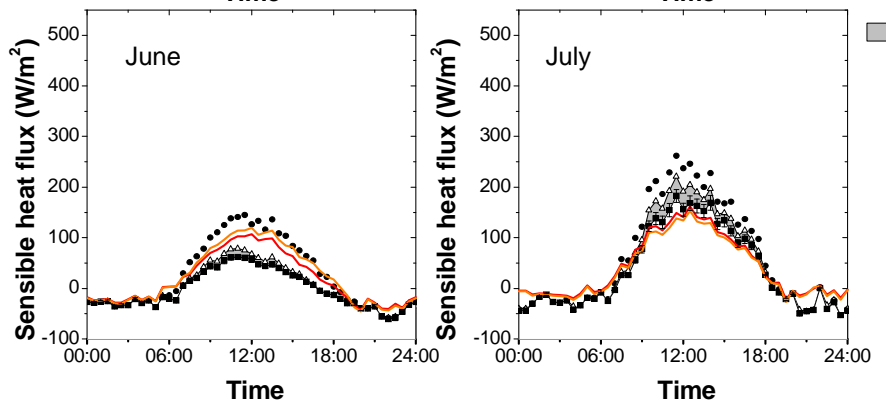

- LE-method = nonadjusted raw data

$\triangle$-Bowen-ratio method

NOAH-MP

with Jarvis scheme

NOAH-MP

with Ball-Berry scheme

Post-closure methods uncertainty band

Figure 8. Measured and simulated monthly average diurnal cycles of sensible heat flux over a winter wheat stand in southwest Germany. For modelling, the NOAH-MP land surface model was used in two configurations. The stomatal resistance was computed either with the empirical Jarvis scheme or the photosynthesis-based Ball-Berry scheme. The grey band shows the post-closure methods uncertainty band computed as the difference between the raw and Bowen ratio-adjusted fluxes. The error bars indicate the random measurement error. In some cases, the error bars are smaller than the size of the symbol and therefore not visible.

Table 4. Evaluation criteria of the Bowen ratio post-closure methods uncertainty bands presented in Figs. 7 and 8.

\begin{tabular}{lccccc}
\hline \multirow{2}{*}{ Month } & \multicolumn{2}{c}{ Band coverage (\%) } & & \multicolumn{2}{c}{ Bound preference (1) } \\
\cline { 2 - 3 } \cline { 5 - 6 } & Jarvis & Ball-Berry & & Jarvis & Ball-Berry \\
\hline Latent heat flux & & & & & \\
April & 35 & 70 & & 0.95 & -0.53 \\
May & 74 & 4 & & -0.29 & -1.67 \\
June & 67 & 33 & & -0.49 & -1.15 \\
July & 7 & 7 & & 1.96 & 2.67 \\
\hline Sensible heat flux & & & & & \\
April & 31 & 0 & & 1.48 & 6.87 \\
May & 0 & 0 & & 4.77 & 11.38 \\
June & 0 & 0 & & 6.37 & 8.31 \\
July & 5 & 5 & & -2.26 & -2.81 \\
\hline
\end{tabular}

to 18:00, simulations with both schemes are fairly well covered by the PUB. The Jarvis scheme results in a lower bound preference $(\mathrm{BP}=-0.71)$, whereas the Ball-Berry scheme has an upper bound preference ( $\mathrm{BP}=0.53)$. In May, the simulated fluxes based on the Jarvis scheme have a BC of $100 \%$. The BC of the Ball-Berry scheme is $67 \%$. Until 14:00 the simulated fluxes are close to the upper bound but still within the band. After 14:00 the sensible heat fluxes move above the upper bound, indicating a systematic overestimation during that period. In June, the BC is high with both schemes. While the fluxes simulated with the Jarvis are midway between both bands, those simulated with the Ball-Berry scheme have an upper bound preference. In July, again simulations with both schemes underestimate the sensible heat flux and are outside the PUB. The BP falls out of the range of -1 to 1 , pointing again to a model deficiency.

The proposed PUB approach enables a more reliable interpretation of the simulation results and allows for more precise identification of periods during which the models show systematic errors. The statement, based on the evaluation on the basis of a single post-closure method, that the default parameterization of NOAH-MP is not suited to simulate the turbulent fluxes must be revised, at least for the latent heat fluxes simulated with the Jarvis scheme. It is no longer jus- 
Table 5. Evaluation criteria of the post-closure methods uncertainty bands (PUBs) presented in Figs. 9 and 10. The PUB was computed from the difference between sensible heat $(H)$ - and latent heat (LE)-adjusted fluxes.

\begin{tabular}{lccccc}
\hline \multirow{2}{*}{ Month } & \multicolumn{2}{c}{ Band coverage (\%) } & & \multicolumn{2}{c}{ Bound preference (1) } \\
\cline { 2 - 3 } \cline { 5 - 6 } & Jarvis & Ball-Berry & & Jarvis & Ball-Berry \\
\hline Latent heat flux & & & & \\
April & 52 & 70 & & 0.58 & -0.57 \\
May & 70 & 4 & & -0.35 & -1.60 \\
June & 71 & 36 & & -0.57 & -1.09 \\
July & 26 & 26 & & 1.22 & 1.77 \\
\hline Sensible heat flux & & & & \\
April & 76 & 76 & & -0.71 & 0.53 \\
May & 100 & 67 & & -0.15 & 0.80 \\
June & 100 & 100 & & 0.07 & 0.40 \\
July & 18 & 14 & -1.57 & -1.73 \\
\hline
\end{tabular}
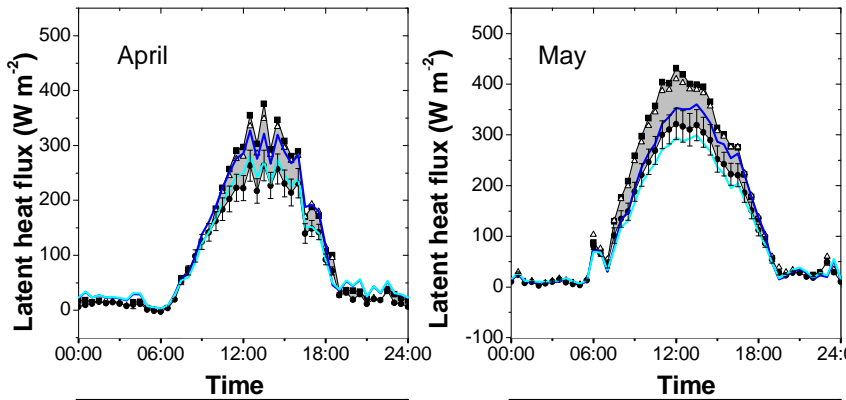

$\triangle$ Bowen-ratio method

$-\mathrm{H}$-method $=$ nonadjusted raw data

- LE-method

NOAH-MP

with Jarvis scheme

NOAH-MP

with Ball-Berry scheme
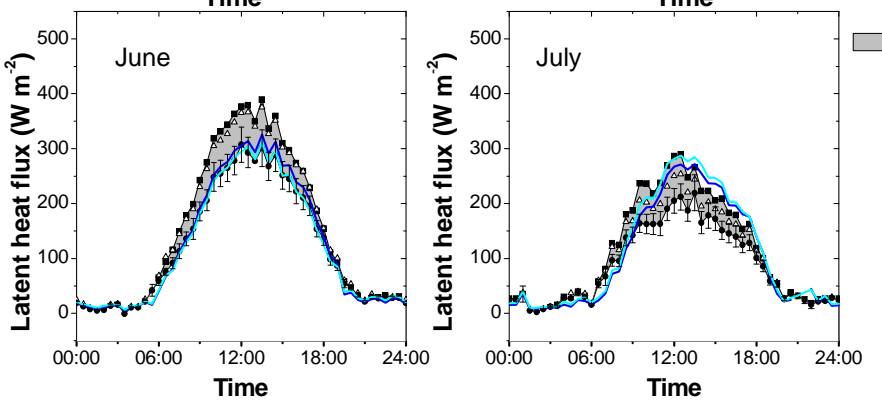

Post-closure methods uncertainty band

Figure 9. Measured and simulated monthly average diurnal cycles of latent heat flux over a winter wheat stand in southwest Germany. For modelling, the NOAH-MP land surface model was used in two configurations. The stomatal resistance was computed either with the empirical Jarvis scheme or the photosynthesis-based Ball-Berry scheme. The grey band shows the post-closure methods uncertainty band (PUB) computed as the difference between sensible heat $(H)$ - and latent heat (LE)-adjusted fluxes. The error bars indicate the random measurement error. In some cases, the error bars are smaller than the size of the symbol and therefore not visible.

tified, because most of the time the simulations of the latent heat flux are well enclosed by the Bowen ratio and the $H-$ LE PUB. Regarding the sensible heat flux, the results are ambiguous. Based on the Bowen ratio PUB, it appears that simulations with both schemes largely overestimate the sensible heat flux from April to May. According to the $H$-LE PUB, however, the simulated fluxes are still in the range of the uncertainty originating from the unclosed energy balance of the EC flux data. What we can reliably state is that (1), in the early morning hours of April, simulations with both schemes overestimate the sensible heat flux; (2) in May, the
Ball-Berry scheme underestimates the latent heat flux, causing the sensible heat flux to move above the upper bound of the $H$-LE PUB; and (3) both schemes show a systematic error over the daytime in July.

The reason for the systematic deviation between measured and simulated sensible heat fluxes during the early morning hours in April might be related to the situation that the ground cover in April, as expressed in the LAI, is low. It is striking that the $H$-LE PUB is extremely narrow during the early morning hours in April, indicating a nearly perfect closure of the energy balance (Fig. 10). Due to the low ground 

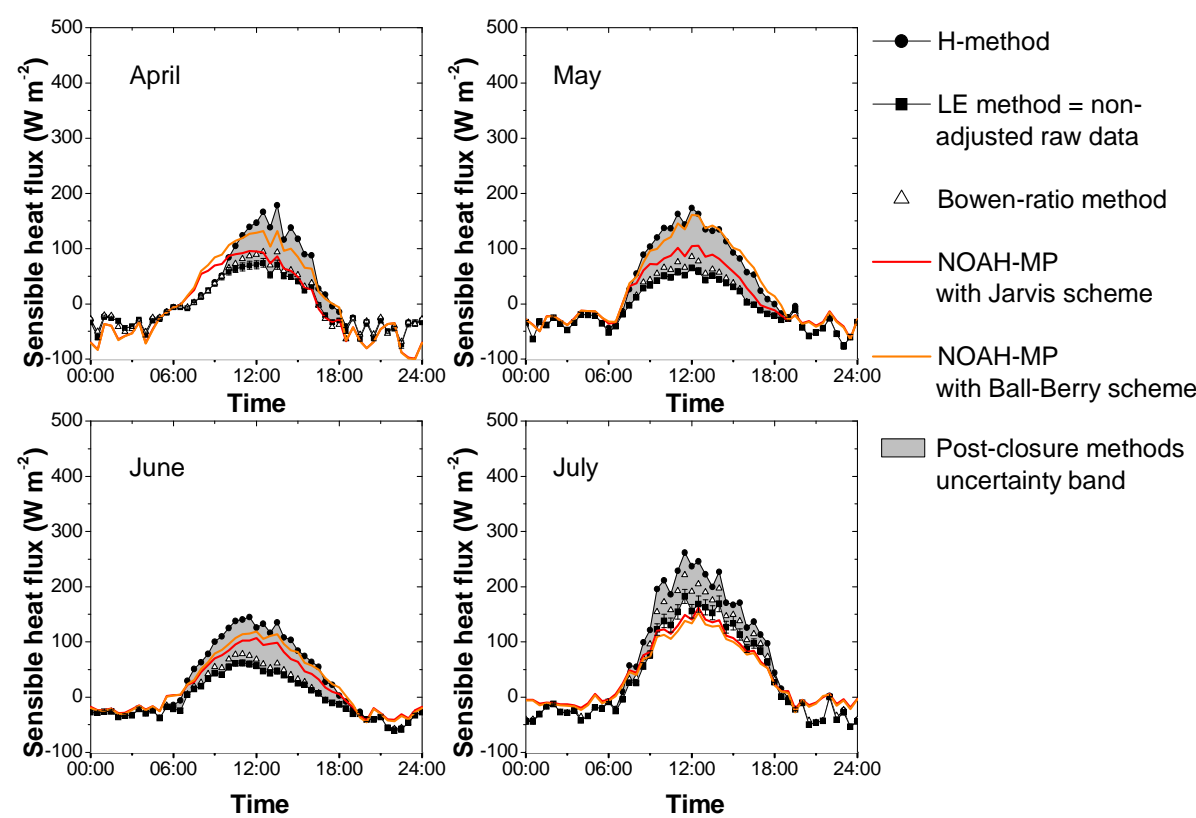

Post-closure methods uncertainty band

Figure 10. Measured and simulated monthly average diurnal cycles of sensible heat flux over a winter wheat stand in southwest Germany. For modelling, the NOAH-MP land surface model was used in two configurations. The stomatal resistance was computed either with the empirical Jarvis scheme or the photosynthesis-based Ball-Berry scheme. The grey band shows the post-closure methods uncertainty band (PUB) computed as the difference between sensible heat $(H)$ - and latent heat (LE)-adjusted fluxes. The error bars indicate the random measurement error. In some cases, the error bars are smaller than the size of the symbol and therefore not visible.

cover in April, the illumination of the ground surface is very heterogeneous. Some positions are shaded by leaves, while others are sunlit. For example, while from 08:00 to 21:00, the coefficient of variation (CV) of the soil heat flux measured at $8 \mathrm{~cm}$ depth $(N=3)$ was $40.2 \%$ in April, in June, due to a more homogeneous ground coverage, the CV declined to $17.9 \%$. Therefore, the possibility that the measured soil heat fluxes were positively biased cannot be excluded. A positively biased soil heat flux reduces the available energy, results in a better closure of the energy balance, and narrows the PUB.

The systematic underestimation of the latent heat flux by Ball-Berry based simulations in May might be explained by a non-adequate parameterization of the Ball-Berry scheme in the case of winter wheat. The default value of the empirical parameter $m$ in Eq. 7, which relates transpiration to $\mathrm{CO}_{2}$ flux, is 9, as for all non-needleleaf forest USGS land use types. Mo and Liu (2001) simulated evapotranspiration (ET) and photosynthesis of winter wheat in the North China Plain and tested, among other things, the Ball-Berry scheme. They used in their simulation for $m$ a value of 11. Repeating the simulation with $m=11$ (data not shown) results in a nearly perfect match in May between simulated and measured nonadjusted latent heat fluxes ( $\mathrm{EF}=99 \%)$, the $\mathrm{BC}$ of the latent heat flux increases from 4 to $41 \%$, the negative bias declines from -76 to $-36 \mathrm{~W} \mathrm{~m}^{-2}$, overall the Jarvis and Ball-Berry simulations move together, and the simulated sensible heat fluxes are also covered by the $H$-LE PUB.
The systematic error in July results from the fact that NOAH-MP does not distinguish between green LAI and total LAI, i.e. the sum of green living and dead senescent leaves. This makes it impossible to adequately describe the surface energy exchange from a ripening winter wheat field. In our parameterization we prescribed that the (green) LAI linearly declines from 4.6 to 0 from mid-June until harvest. This ensures that the transpiration, as under real field conditions, continuously decreases. In the radiation transfer scheme, however, this linearly declining LAI produces the situation of more and more shortwave radiation being absorbed by the ground instead of by the vegetation. Shortly before harvest, the vegetated area is treated like a bare area, which is in disagreement with the real situation in the field. Also, below a fully senescent winter wheat, the ground is still shaded to a large extent, because the total LAI is still high (LAI 3). Implementing into NOAH-MP a green LAI that is used in the stomatal resistance scheme to compute $r_{\mathrm{S}}$ and a total LAI that is applied in the radiation transfer scheme to compute the partitioning of shortwave radiation absorbed by ground and vegetation would most probably improve the simulation result in July.

The random error (instrumental noise plus stochastic error) of the EC flux measurements averaged $13 \%$ of the latent heat flux and $11 \%$ of the sensible heat flux. These numbers agree well with data presented by Mauder et al. (2013), who found that both errors usually range between 10 and $20 \%$ for high-quality data as used in the present study. The instru- 
mental noise was usually one order of magnitude lower than the stochastic error. Overall, the random error was about one order of magnitude lower than the post-closure method error, pointing to the importance of considering this error in analysing EC flux data.

In the literature, a few studies compared Bowen ratioadjusted EC fluxes against a second independent method for measuring the latent heat flux. This provides some experimental indication of the robustness of the Bowen ratio method. Wohlfahrt et al. (2010) tested EC ET rates against independent estimates from micro-lysimeters at a temperate mountain grassland over two measurement campaigns. The authors come to recommend forcing the energy balance closure by adjusting for the average Bowen ratio, meaning that the energy balance is closed on a daily basis by dividing the measured half-hourly $H$ and LE by the daily Bowen ratio. This implies that the Bowen ratio is conserved on a daily basis, but not necessarily the energy balance on halfhourly basis. Scott (2010) compared ET rates obtained with the EC method against the watershed balance over a period of 5 years in semi-desert grassland and desert scrubland catchments in the USA. The author concluded that the justification for forcing the closure using the Bowen ratio method was ambiguous. Nine out of the investigated 13 years showed the same or less disagreement between EC and watershed ET when measured fluxes were not adjusted. Barr et al. (2000) compared EC flux measurements with ET data obtained with the piezometric weighting lysimeter method at a boreal mature aspen stand. Over a period of 20 months, cumulative piezometric ET was $808 \mathrm{~mm}$. Due to the overall low energy balance gap (on average $10 \%$ ), the two applied post-closure methods did not yield distinctly different results. Without flux adjustment, the EC method yielded a cumulative ET of $760 \mathrm{~mm}$. Applying the Bowen ratio post-closure method slightly overestimated ET but led overall to a better agreement with the lysimeter method. The Bowen ratio postclosure method increased measured ET to $836 \mathrm{~mm}$. More unambiguous results were obtained by Schume et al. (2005) and Wilson et al. (2001). Compared to the two other studies described above, the EBC was distinctly lower (about $80 \%$ ). For a temperate mixed European beech-Norway spruce forest canopy, Schume et al. (2005) found a perfect agreement between non-adjusted latent heat flux data and the soil water balance method. Forcing the energy balance closure with the Bowen ratio method resulted in an overestimation of ET by $16 \%$. For a mixed deciduous oak forest, Wilson et al. (2001) compared the EC method with the catchment water balance method. Based on the latter, the 5-year average annual ET was $582 \mathrm{~mm}$. This value agreed very well with non-adjusted ET data measured by the EC technique $(571 \mathrm{~mm}$ per year). The authors did not apply any method for post-closing the energy balance, and do not give data on the Bowen ratio, but it suffices to state that the energy balance gap corresponds to about $143 \mathrm{~mm}$ of vaporized water. Under the climatic conditions at the site they mention (annual rainfall $1333 \mathrm{~mm}$; an- nual ET about $580 \mathrm{~mm}$ ), one can expect the Bowen ratio to be distinctly lower than unity during most of the year. In other words, the Bowen ratio method would assign most of the energy balance gap to the latent heat flux. Hence, also at the study site of Wilson et al. (2001), applying the Bowen ratio method would have overestimated the annual ET. This short review shows that there exist experimental indications that under some conditions the Bowen ratio method, and a fortiori the LE method, might tend to overcorrect the latent heat flux, which fits with our finding that both schemes showed a clear lower bound preference in May and June.

All three post-closure methods assign the energy residual to the latent and/or sensible heat flux. Such approaches assume that the available energy at the surface is measured accurately, which is certainly not the case in the real world. Kohsiek et al. (2007) estimated that the error in the net radiation measurement during the EBEX-2000 campaign was up to $25 \mathrm{~W} \mathrm{~m}^{-2}$. Moreover, in the calculation of the available energy, the canopy storage and energy consumption by photosynthesis (gross primary productivity, GPP), among other things, are usually not considered, because they are not measured with conventional EC systems. Canopy storage becomes particularly important for tall vegetation, but it can also reach $20 \mathrm{~W} \mathrm{~m}^{2}$ at crop sites, in particular during the morning hours (Meyers and Hollinger, 2004). On a daily average, however, this flux cancels out. Energy consumption by photosynthesis can approach fluxes of the same order of magnitude as canopy storage. For an irrigated cotton field, Oncley et al. (2007) computed for the energy consumption by photosynthesis a diurnal average value of $8 \mathrm{~W} \mathrm{~m}^{-2}$ with a half-hourly peak value of formidable $48 \mathrm{~W} \mathrm{~m}^{-2}$. Jacobs et al. (2008) calculated in their study all possible enthalpy changes, such as the soil heat storage, vegetation cover heat storage, dew water heat storage, air mass heat storage, and the photosynthesis energy flux for a grass land site. By doing so, they were able improve the EBR of the EC flux data from 84 to $96 \%$. Also, Leuning et al. (2012) postulated that the closure of the energy balance is possible at half-hourly timescales by paying careful attention to all sources of measurement and data processing errors and by accurately measuring net radiation and every energy storage term needed to calculate the available energy. Therefore, accurate measurement and considering the minor fluxes and storage terms in the calculation of the available energy would certainly help in reducing the energy balance gap, thereby narrowing the PUB and reducing uncertainty.

Recently, Charuchittipan et al. (2014) proposed a further post-closure method. They suggested closing the energy balance based on the buoyancy flux ratio. In this approach, the fraction of the residual attributed to the sensible heat flux depends on the relative contribution of the sensible heat flux to the buoyancy flux. In general, this approach assigns larger fractions of the residual to the sensible heat flux than the Bowen ratio method does. In the context of the PUB, $H$ fluxes calculated with the buoyancy flux ratio method would 
be in between the Bowen ratio- and $H$-adjusted fluxes. The difference between Bowen ratio- and buoyancy flux ratioadjusted fluxes depends strongly on the Bowen ratio. At very high Bowen ratios (> 10), both methods result in very similar adjustments. At lower Bowen ratios, however, the difference between both methods increases. At a measured Bowen ratio of 0.2 and an $\mathrm{EBC}$ of $80 \%$, for example, the Bowen ratio method would assign $17 \%$ of the residual to $H$, while, based on the buoyancy flux ratio method, this fraction increases to $86 \%$ (at $20^{\circ} \mathrm{C}$ ) and the Bowen ratio shifts to 0.44. It remains to be seen whether this novel approach will prove its worth in the future.

In the present paper, PUB was not used to provide formal uncertainties but rather as a qualitative tool to identify periods during which the model definitely showed structural deficiencies. This right-or-wrong decision tool is quite coarse because it filters out only the most obvious failure periods. Beyond this, it should be possible to use PUB, for example, in model inversion. Here, the BC could be directly used as an objective function. One could either search in the parameter space for the set of parameters with the highest BC or search for sets of parameters above a prescribed $\mathrm{BC}$ threshold. In the latter case one would get a distribution of parameters. In the GLUE (generalized likelihood uncertainty estimation; Beven and Binley, 2014) approach, which is well established in hydrology, the PUB could be used as a criterion to distinguish between behavioural and un-behavioural model runs. Model parameterizations below a prescribed BC may be regarded as non-behavioural and thus excluded from the further uncertainty analysis. Within the framework of a Bayesian approach for parameter estimation (see e.g. Braakhekke et al., 2013), PUB could be used to constrain the likelihood function needed to compute the joined probability density.

\section{Conclusions}

We must be aware of the fact that, with computational adjustment of the measured fluxes, we might add a substantial bias to the observed data, no matter which post-closure method we choose. In our study, the difference between the post-closing methods was up to $110 \mathrm{~W} \mathrm{~m}^{-2}$. The possible error introduced by the post-closure method is about one order of magnitude larger than the random measurement error. This underlines the need to critically assess and communicate the possible error in eddy covariance flux data resulting from the missing energy balance closure. The proposed post-closure methods uncertainty band (PUB) approach is an effective way to achieve this. Working with only one postclosure method may result in serious misinterpretations in model-data comparisons. For narrowing the PUB, we urgently need more research on the true nature of the energy balance residual.
Acknowledgements. We gratefully acknowledge the financial support from the German Research Foundation (DFG) as part of Research Unit 1695 "Agricultural Landscapes under Global Climate Change - Processes and Feedbacks on a Regional Scale". We thank the farmers Mr Bosch senior and $\mathrm{Mr}$ Bosch junior for their cooperation and the two anonymous reviewers for their helpful and inspiring comments.

Edited by: T. Keenan

\section{References}

Alavi, N., Berg, A. A., Warland, J. S., Parkin, G., Verseghy, D., and Bartlett, P.: Evaluating the impact of assimilating soil moisture variability data on latent heat flux estimation in a land surface model, Can. Water Resour. J., 35, 157-172, 2010.

Baldocchi, D., Reichstein, M., Papale, D., Koteen, L., Vargas, R., Agarwal, D., and Cook, R.: The role of trace gas flux networks in the biogeosciences, Eos, 93, 217-218, 2012.

Barr, A. G., King, K. M., Gillespie, T. J., den Hartog, G., and Neumann, H. H.: A comparison of Bowen ratio and eddy correlation sensible and latent heat flux measurements above deciduous forest, Bound.-Lay. Meteorol., 71, 21-41, 1994.

Barr, A. G., Kamp, G. V. D., Schmidt, R., and Black, T. A.: Monitoring the moisture balance of a boreal aspen forest using a deep groundwater piezometer, Agric. For. Meteorol., 102, 1324, 2000.

Beven, K. and Binley, A.: GLUE: 20 years on, Hydrol. Process. 28, 5987-5918, 2014.

Blanken, P. D., Black, T. A., Yang, P. C., Neumann, H. H., Nesic, Z., Staebler, R., Den Hartog, G., Novak, M. D., and Lee, X.: Energy balance and canopy conductance of a boreal aspen forest: Partitioning overstory and understory components, J. Geophys. Res.-Atmos., 102, 28915-28927, 1997.

Blyth, E., Gash, J., Lloyd, A., Pryor, M., Weedon, G. P., and Shuttleworth, J.: Evaluating the JULES land surface model energy fluxes using FLUXNET data, J. Hydrometeorol., 11, 509-519, 2010.

Braakhekke, M. C., Wutzler, T., Beer, C., Kattge, J., Schrumpf, M., Ahrens, B., Schöning, I., Hoosbeek, M. R., Kruijt, B., Kabat, P., and Reichstein, M.: Modeling the vertical soil organic matter profile using Bayesian parameter estimation, Biogeosciences, 10, 399-420, doi:10.5194/bg-10-399-2013, 2013.

Carrer, D., Lafont, S., Roujean, J., Calvet, J., Meurey, C., Le Moigne, P., and Trigo, I. F.: Incoming solar and infrared radiation derived from METEOSAT: Impact on the modeled land water and energy budget over France, J. Hydrometeorol., 13, 504-520, 2012.

Charuchittipan, D., Babel, W., Mauder, M., Leps, J. P., and Foken, T. T.: Extension of the averaging time in eddy-covariance measurements and its effect on the energy balance closure, Bound.Lay. Meteorol., 152, 303-327. 2014.

Chen, F. F. and Dudhia, J.: Coupling and advanced land surfacehydrology model with the Penn State-NCAR MM5 modeling system, Part I: Model implementation and sensitivity, Mon. Weather Rev., 129, 569-585, 2001.

Chen, F. F., Manning, K. W., Lemone, M. A., Trier, S. B., Alfieri, J. G., Roberts, R., Tewari, M., Niyogi, D., Horst, T. W., Oncley, S. 
P., Basara, J. B., and Blanken, P. D.: Description and evaluation of the characteristics of the NCAR high-resolution land data assimilation system, J. Appl. Meteorol. Clim., 46, 694-713, 2007.

Dudhia, J.: A nonhydrostatic version of the Penn State-NCAR mesoscale model: Validation tests and simulation of an Atlantic cyclone and cold front, Mon. Weather Rev., 1493-1513, 1993.

Falge, E., Reth, S., Brüggemann, N., Butterbach-Bahl, K., Goldberg, V., Oltchev, A., Schaaf, S., Spindler, G., Stiller, B., Queck, R., Köstner, B., and Bernhofer, C.: Comparison of surface energy exchange models with eddy flux data in forest and grassland ecosystems of Germany, Ecol. Model., 188, 174-216, 2005.

Farquhar, G. D., von Caemmerer, S., and Berry, J. A.: A biochemical model of photosynthetic $\mathrm{CO}_{2}$ assimilation in leaves of $\mathrm{C} 3$ species, Planta, 149, 78-90, 1980.

Foken, T. T.: Der Bayreuther Turbulenzknecht, Universität Bayreuth, 19 pp., 1999.

Foken, T. T.: The energy balance closure problem: An overview, Ecol. Appl., 18, 1351-1367, 2008

Gayler, S., Wöhling, T., Grzeschik, M., Ingwersen, J., Wizemann, H., Warrach-Sagi, K., Högy, P., Attinger, S., Streck, T., and Wulfmeyer, V.: Incorporating dynamic root growth enhances the performance of Noah-MP at two contrasting winter wheat field sites, Water Resour. Res., 50, 1337-1356, 2014.

Gerken, T., Babel, W., Hoffmann, A., Biermann, T., Herzog, M., Friend, A. D., Li, M., Ma, Y., Foken, T., and Graf, H.-F.: Turbulent flux modelling with a simple 2-layer soil model and extrapolated surface temperature applied at Nam Co Lake basin on the Tibetan Plateau, Hydrol. Earth Syst. Sci., 16, 1095-1110, doi:10.5194/hess-16-1095-2012, 2012.

Gielen, B., Verbeeck, H., Neirynck, J., Sampson, D. A., Vermeiren, F., and Janssens, I. A.: Decadal water balance of a temperate Scots pine forest (Pinus sylvestris L.) based on measurements and modelling, Biogeosciences, 7, 1247-1261, doi:10.5194/bg7-1247-2010, 2010.

Hayashi, M., Jackson, J. F., and Xu, L.: Application of the versatile soil moisture budget model to estimate evaporation from prairie grassland, Can. Water Resour. J., 35, 187-208, 2010.

Ingwersen, J., Steffens, K., Högy, P., Warrach-Sagi, K., Zhunusbayeva, D., Poltoradnev, M., Gäbler, R., Wizemann, H., Fangmeier, A., Wulfmeyer, V., and Streck, T.: Comparison of Noah simulations with eddy covariance and soil water measurements at a winter wheat stand, Agric. For. Meteorol., 151, 345-355, 2011.

IUSS: Working Group WRB: World Reference Base for Soil Resources 2006, first update 2007, Rome, 148 pp., 2007.

Jacobs, A. F. G., Heusinkveld, B. G., and Holtslag, A. A. M.: Towards closing the surface energy budget of a mid-latitude grassland, Bound.-Lay. Meteorol., 126, 125-136, 2008.

Kohsiek, W., Liebethal, C., Foken, T., Vogt, R., Oncley, S. P., Bernhofer, C., and Debruin, H. A. R.: The Energy Balance Experiment EBEX-2000, Part III: Behaviour and quality of the radiation measurements, Bound.-Lay. Meteorol., 123, 55-75, 2007.

Leuning, R., van Gorsel, E., Massman, W. J., and Isaac, P. R.: Reflections on the surface energy imbalance problem, Agric. For. Meteorol., 156, 65-74, 2012.

LI-COR Inc.: EddyPro, 2012

Mauder, M. and Foken, T.: Impact of post-field data processing on eddy covariance flux estimates and energy balance closure, Meteorol. Z., 15, 597-609, 2006.
Mauder, M. and Foken, T.: Documentation and Instruction Manual of the Eddy-Covariance Software Package TK3, Universität Bayreuth, Abteilung Mikrometeorologie, 60 pp., 2011.

Mauder, M., Cuntz, M., Drüe, C., Graf, A., Rebmann, C., Schmid, H. P., Schmidt, M., and Steinbrecher, R.: A strategy for quality and uncertainty assessment of long-term eddy-covariance measurements, Agric. For. Meteorol., 169, 122-135, 2013.

Meyers, T. P. and Hollinger, S. E.: An assessment of storage terms in the surface energy balance of maize and soybean, Agric. For. Meteorol., 125, 105-115, 2004.

Mo, X. and Liu, S.: Simulating evapotranspiration and photosynthesis of winter wheat over the growing season, Agric. For. Meteorol., 109, 203-222, 2001.

Moore, C. J.: Frequency response corrections for eddy correlation systems, Bound.-Lay. Meteorol., 37, 17-35, 1986.

Niu, G., Yang, Z., Mitchell, K. E., Chen, F., Ek, M. B., Barlage, M., Kumar, A., Manning, K., Niyogi, D., Rosero, E., Tewari, M., and Xia, Y.: The community Noah land surface model with multiparameterization options (Noah-MP): 1. Model description and evaluation with local-scale measurements, J. Geophys. Res.Atmos., 116, 1-19, 2011.

Oncley, S. P., Foken, T., Vogt, R., Kohsiek, W., DeBruin, H. A. R., Bernhofer, C., Christen, A., van Gorsel, E., Grantz, D., Feigenwinter, C., Lehner, I., Liebethal, C., Liu, H., Mauder, M., Pitacco, A., Ribeiro, L., and Weidinger, T.: The energy balance experiment EBEX-2000, Part I: Overview and energy balance, Bound.Lay. Meteorol., 123, 1-28, 2007.

Schotanus, P., Nieuwstadt, F. T. M., and DeBruin, H. A. R.: Temperature measurement with a sonic anemometer and its application to heat and moisture fluctuations., Bound.-Lay. Meteorol., 26, 81-93, 1983.

Schume, H., Hager, H., and Jost, G.: Water and energy exchange above a mixed European Beech - Norway Spruce forest canopy: A comparison of eddy covariance against soil water depletion measurement, Theor. Appl. Climatol., 81, 87-100, 2005.

Scott, R. L.: Using watershed water balance to evaluate the accuracy of eddy covariance evaporation measurements for three semiarid ecosystems, Agric. For. Meteorol., 150, 219-225, 2010.

Skamarock, W. C., Klemp, J. B., Dudhia, J., Gill, D. O., Barker, D. M., Duda, M. G., Huang, X. Y., Wang, W., and Powers, J. G.: A description of the Advanced Research WRF Version 3, 125 pp., 2008.

Spank, U., Schwärzel, K., Renner, M., Moderow, U., and Bernhofer, C.: Effects of measurement uncertainties of meteorological data on estimates of site water balance components, J. Hydrol., 492, 176-189. 2013.

Staudt, K., Falge, E., Pyles, R. D., Paw U, K. T., and Foken, T.: Sensitivity and predictive uncertainty of the ACASA model at a spruce forest site, Biogeosciences, 7, 3685-3705, doi:10.5194/bg-7-3685-2010, 2010.

Stoy, P. C., Mauder, M., Foken, T., Marcolla, B., Boegh, E., Ibrom, A., Arain, M. A., Arneth, A., Aurela, M., Bernhofer, C., Cescatti, A., Dellwik, E., Duce, P., Gianelle, D., van Gorsel, E., Kiely, G., Knohl, A., Margolis, H., Mccaughey, H., Merbold, L., Montagnani, L., Papale, D., Reichstein, M., Saunders, M., Serrano-Ortiz, P., Sottocornola, M., Spano, D., Vaccari, F., and Varlagin, A.: A data-driven analysis of energy balance closure across FLUXNET research sites: The role of landscape scale heterogeneity, Agric. For. Meteorol., 171-172, 137-152, 2013. 
Twine, T. E., Kustas, W. P., Norman, J. M., Cook, D. R., Houser, P. R., Meyers, T. P., Prueger, J. H., Starks, P. J., and Wesely, M. L.: Correcting eddy-covariance flux underestimates over a grassland, Agric. For. Meteorol., 103, 279-300, 2000.

Webb, E. K., Pearman, G. I., and Leuning, R.: Correction of the flux measurements for density effects due to heat and water vapour transfer, Q. J. R. Meteorolog. Soc., 106, 85-100, 1980.

Wilson, K. B., Hanson, P. J., Mulholland, P. J., Baldocchi, D. D., and Wullschleger, S. D.: A comparison of methods for determining forest evapotranspiration and its components: Sap-flow, soil water budget, eddy covariance and catchment water balance, Agric. For. Meteorol., 106, 153-168, 2001.
Wilson, K. K., Goldstein, A., Falge, E., Aubinet, M., Baldocchi, D., Berbigier, P., Bernhofer, C., Ceulemans, R., Dolman, H., Field, C., Grelle, A., Ibrom, A., Law, B. E., Kowalski, A., Meyers, T., Moncrieff, J., Monson, R., Oechel, W., Tenhunen, J., Valentini, R., and Verma, S.: Energy balance closure at FLUXNET sites, Agric. For. Meteorol., 113, 223-243, 2002.

Winter, J. M. and Eltahir, E. A. B.: The sensitivity of latent heat flux to changes in the radiative forcing: A framework for comparing models and observations, J. Clim., 23, 2345-2356, 2010.

Wohlfahrt, G., Irschick, C., Thalinger, B., Hortnagl, L., Obojes, N.,, and Hammerle, A.: Insights from Independent Evapotranspiration Estimates for Closing the Energy Balance: A Grassland Case Study, Vadose Zone J., 9, 1025-1033, 2010. 